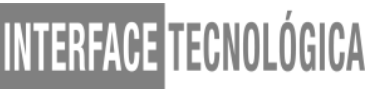

\section{OS BENEFÍCIOS SOCIOAMBIENTAIS DAS EMBALAGENS SUSTENTÁVEIS}

\section{THE SOCIAL AND ENVIRONMENTAL BENEFITS OF SUSTAINABLE PACKAGING}

Agnaldo Fernandes dos Santos Junior - Juninho_taqua@ outlook.com

André Luiz Oliveira - andre.adv@uol.com.br

Faculdade de Tecnologia de Taquaritinga (FATEC) -SP -Brasil

DOI: 10.31510/infa.v16i2.645

\section{RESUMO}

O presente trabalho se ocupa em traçar um panorama relacionado a aspectos pontuais que possam conduzir a políticas públicas voltadas à questão ambiental. A lei maior do país, Constituição Federal de 1988 traz um capítulo específico sobre a questão ambiental, impondo ao poder público e à coletividade o dever de defender e preservar o meio ambiente para as futuras gerações. Para tanto, são necessárias ações que possam mitigar um dos maiores problemas enfrentados no país, no que tange às políticas ambientais: a geração de resíduos. Neste contexto, as embalagens em geral, consideradas catalisadores da questão central, contribuem significativamente para o agravamento deste cenário. Como alternativa, a pesquisa identifica os principais benefícios do uso de embalagens sustentáveis como instrumento para a redução da geração de resíduos sólidos.

Palavras-chave: Sustentabilidade. Resíduos sólidos. Embalagens sustentáveis. Gestão Ambiental.

\begin{abstract}
This research aims to highlight an outlook related to specific aspects that may lead to public policies related to the environmental issue. The largest law of the country, Federal Constitution of 1988 brings a specific chapter on the environmental issue, imposing on the public power and the community the duty to defend and preserve the environment for future generations. Therefore, actions are needed that can mitigate one of the biggest problems faced in the country regarding environmental policies: waste generation. In this context, packaging in general, considered a catalyst for the central issue, contributes significantly to the worsening of this scenario. Alternatively, the research identifies the main benefits of using sustainable packaging as a tool for reducing solid waste generation.
\end{abstract}

Keywords: Sustainability. Solid waste. Sustainable packaging. Environmental management.

\section{INTRODUÇÃO}

De acordo com Januário (2017), em todo o Planeta, evidencia-se uma necessidade crescente de soluções sustentáveis e coerentes para os problemas oriundos da geração excessiva de resíduos sólidos, fruto de uma sociedade de consumo. Essa problemática parece 
ser mais complexa em países em desenvolvimento, onde, como resultado do crescimento econômico, da urbanização e da industrialização, o volume crescente e os tipos de resíduos estão se tornando um sério problema para os governos nacionais e locais, dificultando a possibilidade de que se garanta uma gestão efetiva e sustentável dos resíduos, preocupação que se apresenta crescente em todo o mundo.

O presente artigo traça um panorama que possibilite uma melhor compreensão sobre a gestão ambiental, além de tentar identificar os principais problemas que a indústria pode enfrentar para se adaptar à um conceito ecológico mais consistente, além de proporcionar uma visão holística sobre qual é o impacto dos resíduos deixados pelas embalagens descartáveis e não descartáveis.

Necessária se faz, portanto, a compreensão de que:

"Estamos diante de um momento crítico na história da terra, em uma época em que a
humanidade deve escolher o seu futuro. À medida que o mundo se torna cada vez
mais independente e frágil [...]. [...] Devemos somar forças para gerar uma sociedade
sustentável global baseada no respeito pela natureza, nos direitos humanos
universais, na justiça econômicas e numa cultura da paz. Para chegar a este
propósito, é imperativo que nós, os povos da terra, declaremos nossa
responsabilidade uns para com os outro, com a grande comunidade da vida e com as
futuras gerações" (CARTA DA TERRA, ONU, 2002).

É possível notar que não somente os consumidores têm cobrado uma posição da empresa em favor da sustentabilidade, mas também alguns órgãos estimulam as empresas a adotarem uma preocupação com o meio ambiente.

Segundo Cajazeira (1998), essa atenção globalizada, centrada na atenção às questões ecológicas, foram repassados às indústrias através de diversas pressões, até mesmo financeiras, pois bancos e instituições evitam formalizar relações jurídicas com empresas que possuem um histórico ruim com relação às questões ambientais.

O objetivo deste trabalho é evidenciar a necessidade da adoção de ações que conduzam à sustentabilidade, abordando mais especificamente a questão das embalagens como geradoras de resíduos e os benefícios ambientais decorrentes da utilização de embalagens consideradas sustentáveis.

A justificativa desta pesquisa reside no fato de que o padrão de consumo da sociedade capitalista impõe pressão sobre os recursos naturais, principalmente nos países industrializados. Se os padrões desses países forem mantidos e adotados por outros países, 
estará comprometida a capacidade do Planeta de suportar este cenário, podendo ocorrer um colapso na disponibilidade de recursos naturais (SCHULTZ, 2002).

\section{GESTÃO AMBIENTAL}

De acordo com a resolução CONAMA n 306/2002, anexo 1 - Inciso X, a expressão "gestão ambiental" corresponde à direção, condução e controle do uso de recursos naturais, riscos e das emissões para o meio ambiente, através da implementação do sistema de gestão ambiental.

Segundo Marques (2015), trata-se de uma técnica administrativa empresarial com foco e prioridade no desenvolvimento sustentável de uma organização, trabalhando na conscientização também dos profissionais, motivando a adoção de comportamentos e técnicas que reduzam ou eliminem consideravelmente o impacto ambiental das atividades da empresa na utilização de recursos da natureza

Para Brito (2015), pode ser compreendida como uma área ainda relativamente nova, que surgiu devido à grande demanda por parte dos ecologistas e empresas, no sentido de que fossem adotadas políticas que alinhem os interesses da empresa com a exploração racional dos recursos naturais.

\subsection{Porque uma empresa deve melhorar seu desempenho ambiental}

Segundo Moura (2011), a questão ambiental tem se mostrado em evidência devido à evolução dos meios de comunicação, uma vez que qualquer desastre ambiental é facilmente noticiado em segundos, razão pela qual as organizações constaram que a qualidade ambiental tem se tornado um item fundamental para os clientes.

Manzini e Vezzoli (2005), partindo dessa constatação, afirmam que a sustentabilidade ambiental é um alvo a ser atingido e não somente uma direção a ser seguida. De acordo com os autores, a real ideia consiste no fato de que nem tudo que apresente melhorias ao meio ambiente pode ser considerado de fato sustentável.

De acordo com Holmberg (2012), para que a organização seja considerável realmente sustentável, é necessário que se atendam os seguintes requisitos:

1) Consistir-se primordialmente em recursos renováveis (e em paralelo assegurando a renovação); 


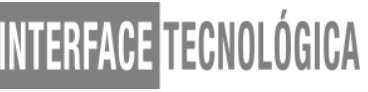

2) Potencializando o emprego de recursos não renováveis (conhecidos como o ar, água e o território);

3) Não aglomerar lixo que o ecossistema não seja capaz de renaturalizar;

Moura (2011) afirma que a empresa tem a obrigação de atender as necessidades dos clientes que consomem seus produtos, sendo o principal objetivo da organização. Prossegue o autor mencionando que, para a sobrevivência da empresa no mundo corporativo, ela deve se ater aos três pilares da sustentabilidade, que a longo prazo determinam sua existência.

Segundo Elkington (2001), os três pilares são:

- Resultado econômico: Prestação de serviços e produzir bens de qualidade, abordar práticas administrativas eficientes e eficazes, conduzindo a organização controlando os números e resultados dos trabalhos da empresa, para que a mesma não encerre suas atividades.

- Qualidade ambiental: o encerramento das atividades da empresa está diretamente ligado com as atitudes tomadas diante da sociedade (representada pela comunidade que participa de órgãos ambientais, mídias, ONGs etc.), evitando a poluição do ar e comprometimento dos recursos hídricos, o descarte incorreto de resíduos sólidos e evitando também a fabricação de produtos agressivos ao meio ambiente de maneira geral.

- Responsabilidade Social: está ligada diretamente às atitudes tomadas pela empresa, com relação a fatores como injustiças sociais, caráter de seus colaboradores, a transparência quanto as informações prestadas, a diversidade de pessoas que trabalham na empresa e principalmente respeito pelas minorias étnicas.

Ao compreender a importância de a empresa melhorar seu desempenho ambiental, resta evidente que ela não deve ser restrita somente ao pessoal de produção ou ao seu setor ambiental, deve englobar toda a direção, gerência, projetistas e operários, para que a organização mude sua forma de atuar no mercado. (MOURA, 2011, p. 63).

\subsection{Normas Ambientais}

Para que uma empresa melhore seu desempenho ambiental, se faz necessário que a mesma adote e respeite uma série de normas, impostas por dois órgãos regulamentadores: a ABNT (Associação Brasileira de Normas Técnicas) que é a representante da ISO no Brasil e a norma diretamente ligada ao Sistema de Gestão Ambiental (ABNT NBR ISO 14001:2004) e 
o CONAMA (Conselho Nacional do Meio Ambiente), que institui também uma legislação que disciplina a ação antrópica no meio ambiente.

Segundo Silva (2011), a ISO é uma organização não governamental, sediada em Genebra - Suíça, com a finalidade de determinar normas representativas que possibilitem acordos entre vários países do mundo. Possui aproximadamente 100 países membros, que decidem através do direito ao voto como serão estabelecidas as normas. O Brasil participa diretamente como fundador e com direito a voto, através da Associação Brasileira de Normas Técnicas, como já mencionado.

De acordo com o Ministério do Meio Ambiente (MMA, 2011), o CONAMA é o órgão consultivo e deliberativo do Sistema Nacional do Meio Ambiente-SISNAMA, foi instituído pela Lei 6.938/81, que dispõe sobre a Política Nacional do Meio Ambiente, regulamentada pelo Decreto 99.274/90. Foi criado e constituído em 1981 no Congresso Nacional Brasileiro.

Segundo a ABNT, 2004 p. 1, a NBR ISO 14001:2004:

\begin{abstract}
especifica os requisitos relativos a um sistema da gestão ambiental, permitindo a uma organização desenvolver e implementar uma política e objetivos que levem em conta os requisitos legais e outros requisitos por ela subscritos e informações referentes aos aspectos ambientais significativos. Aplica-se aos aspectos ambientais que a organização identifica como aqueles que possa controlar e aqueles que possa influenciar. Em si, esta Norma não estabelece critérios especificas de desempenho ambiental. (ABNT, 2004 p.1)
\end{abstract}

De acordo com o disposto na legislação, são atos do CONAMA:

- $\quad$ Resoluções - quando se tratar de deliberações vinculadas às diretrizes e normas técnicas relacionadas à proteção do meio ambiente e do uso de recursos naturais;

- Moções - sempre que se tratar de protestos, de qualquer natureza ligados à questão ambiental;

- $\quad$ Recomendações - Ao se tratar de manifestação acerca da implementação de políticas, programas ou normas com influência na área ambiental;

- Proposições - quando alguma matéria é encaminhada ao Conselho de Governo, ou às Comissões do Senado Federal e da Câmara dos Deputados;

- Decisões - ao deliberar sobre multas de caráter ambiental e outras penalidades impostas pelo IBAMA, em última instância administrativa e grau de recurso, por meio de deliberação da Câmara Especial Recursal - CER. 


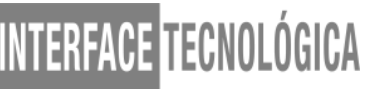

\section{PROCEDIMENTOS METODOLÓGICOS}

A presente pesquisa possui caráter descritivo e exploratório e procura evidenciar uma questão totalmente voltada para um dos principais desafios da agenda ambiental brasileira: a necessidade de adoção de práticas oriundas de políticas públicas que possam reduzir a quantidade de resíduos sólidos gerados no cotidiano.

Para tanto, foi traçado um panorama geral a respeito dos benefícios oriundos da adoção de embalagens sustentáveis, como alternativa à utilização das embalagens tradicionais que acabam contribuindo para extrapolar a capacidade de aterros e lixões (proibidos pela legislação ambiental).

Segundo Gil (2006), o objetivo de uma pesquisa exploratória é compreender um assunto ainda pouco estudado.

\section{RESULTADOS E DISCUSSÃO}

\subsection{A importância das embalagens para o mercado e proteção dos produtos}

Faz parte do senso comum em uma sociedade de consumo o fato de que as embalagens são necessárias, para que haja uma proteção dos produtos a serem comercializados e consumidos. Segundo Romano (2018), o investimento em embalagens tem como objetivo garantir a integridade de todo e qualquer produto, a fim de que se conserve o produto intacto até o consumidor.

Ainda segundo o autor, a função principal das embalagens é proteger o produto, mas sua importância pode ser considerada ainda maior, exercendo outras funções, como exemplo:

- Acomodar os produtos adequadamente;

- Fornecer todas as informações necessárias, bem como, valor nutricional, quantidade oferecida etc.;

- Influenciar o consumidor a comprar o produto.

De acordo com dados do site Intelipost (2017), 60\% dos brasileiros avaliam a embalagem como mais importante, uma vez que a embalagem corresponde ao primeiro contato do consumidor com o bem a ser adqurido, [...] pois tem o poder de transmitir sensações que levem o consumidor a comprar o produto. 


\subsection{Tipos de embalagens}

De acordo com a literatura (Siqueira, 2018; Romano, 2018), as embalagens são peças fundamentais, existindo diferentes tipos, cada qual com seus benefícios e especificidades, além dos materiais que a compõem, como por exemplo:

- Madeira: um dos materiais utilizados para levar grande quantidade de produtos, qualificado como embalagens terciária ou quaternária.

- Papelão ou Papel: material leve, de fácil armazenagem e completamente reciclável, qualificados como embalagens primárias e secundárias.

- Vidro: matéria mais frágil, difícil armazenagem, qualificado como embalagens primária.

- $\quad$ Plástico: muito utilizadas, por ser facilmente moldáveis e adaptáveis a diversos tamanhos.

- Outras: Isopor, Tetra Pak, laminados etc., cada um com suas características específicas e adequadas a certos tipos de produtos.

Segundo dados do Ministério do Meio Ambiente (2017), cada material tem um tempo determinado para sua decomposição, situação que se reflete nas embalagens dos produtos, que acabam se tornando resíduos sólidos a serem descartados. O quadro 1 apresenta um panorama sobre o tempo de decomposição dos materiais na natureza.

Ilustração 1 - Decomposições dos materiais

\begin{tabular}{|c|c|}
\hline Materiais & Tempo de decomposição na natureza \\
\hline Papel & De 3 a 6 meses \\
\hline Tecidos & De 6 meses a 1 ano \\
\hline Metais & Mais de 100 anos \\
\hline Alumínio & Mais de 200 anos \\
\hline Plástico & Mais de 400 anos \\
\hline Vidro & Mais de 1000 anos \\
\hline
\end{tabular}

Fonte: MMA (2017).

Segundo Siqueira (2018), o vidro é um dos materiais mais poluentes que existe, seguido pelo plástico (quando não há um descarte correto). Por sua vez, o papel é o que leva menos tempo para se decompor (levando a acreditar que é umas das melhores alternativas), embora o vidro seja considerado uma forma de embalagem sustentável. 


\subsection{Os impactos ambientais das embalagens}

Segundo o Ministério do Meio Ambiente (MMA, 2017), um terço do lixo doméstico é composto por embalagens, sendo que aproximadamente $80 \%$ das embalagens são utilizadas apenas uma vez e descartadas de forma incorreta, o que gera aumento no volume e superlotações nos lixões.

Em reportagem específica sobre o tema, a REVISTA ISTO É (2008), afirma que o grande número de resíduos, provocam anualmente a morte de aproximadamente 1 milhão de aves e mais de 100 mil mamíferos marinhos. No Brasil, um quinto do lixo produzido é provocado por embalagens e quase 25 mil toneladas vão parar nos depósitos de lixos todos os dias.

O MMA (2017), acredita que há uma série de impactos que as embalagens podem trazer, através do seu consumo excessivo e descarte incorreto, dentre as quais:

- $\quad$ Esgotamento dos lixões e aterros;

- Dificuldade na degradação de resíduos orgânicos;

- $\quad$ Morte de animais que ingerem esses resíduos;

- $\quad$ Poluição visual.

De acordo com o órgão oficial, esses impactos podem ser reduzidos, se houver uma diminuição do consumo desnecessário e a separação correta dos lixos seja elevada à categoria de política pública obrigatória pela legislação. (MMA, 2017).

\subsection{Embalagens sustentáveis}

Segundo o site Perform Pak (2018), as embalagens sustentáveis são feitas de recursos orgânicos, recicláveis ou biodegradáveis, cuja produção demanda menos energia e menor uso dos recursos naturais.

De acordo com o Website eCicle (2019), todos os dias novos tipos e modelos de embalagens são projetados, como por exemplos as embalagens biodegradáveis de fibra de côco, de papel reciclado, entre outros materiais que substituem o plástico convencional. O site mencionado (especializado no tema objeto deste artigo), elenca alguns exemplos de embalagens sustentáveis e suas vantagens: 


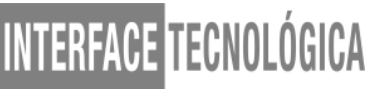

- Embalagens de Vidro: São consideradas sustentáveis por não liberarem substância tóxica, além de serem facilmente reutilizadas;

- Embalagens de alumínio: Apesar de necessitarem de mineradoras, as embalagens de alumínios, são consideradas infinitamente recicláveis;

- Embalagens de cogumelo: produzidas através das raízes do cogumelo, cujo custo é elevado, mas na natureza se decompõe facilmente;

- Embalagens de papel reciclado: potencializa o tempo de vida dos produtos e maximiza o valor extraído dos inputs, gerando uma economia de energia. Como fragilidade, o fato de que a cada reciclagem perde-se qualidade e possibilidades de nova reciclagem.

\subsection{Os benefícios das embalagens sustentáveis}

A embalagem trata-se de uma parte integrante que se faz necessária para dispor os produtos à sociedade. Além disso, exige que haja uma sistemática de retorno, uma vez descartada após o uso do produto. Compreender a sistemática da embalagem é observar todo o ciclo de vida dela, desde sua produção, seu uso e até mesmo sua reutilização (ABRE; CETESB, 2016).

Segundo Grazziotin e Vieira (2014), a embalagem é a principal ligação visual de comunicação entre o consumidor, o produto e marca, pois é através dela é que o consumidor irá escolher se irá consumir o produto ou não.

De acordo com Moura e Banzato (1997), as embalagens podem ser separadas por funções, utilidade, origem, materiais e orientações pós-uso. Os autores adotam a seguinte classificação:

- $\quad$ Embalagem primária: contém o produto, é através dela que são acometidas as vendas;

- $\quad$ Embalagens secundária: é o que preserva a embalagem primária;

- $\quad$ Embalagens terciária: protege e preserva as duas primeiras;

- Embalagens quaternária: recipiente que facilita a movimentação e armazenamento;

- $\quad$ Embalagens de quinto nível: a unidade disposta em contêiner.

As embalagens ainda podem ter outra função, dessa vez em relação ao meio ambiente, uma vez que, a busca pela minimização do impacto ambiental é também um papel das 


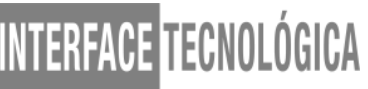

embalagens e portanto cabe a empresa, ponderar a função ambiental sobre essa questão (MESTRINER, 2002; PEREIRA, 2003).

Segundo o Website eCicle (2019), um dos benefícios causados pelas embalagens sustentáveis é a redução de danos causados pelos descartes de embalagens comuns, além de não demandar muita energia e recursos para sua produção, e proporcionar impactos ambientais bem menores do que o usual.

Outros benefícios que as embalagens sustentáveis agregam, são identificados:

- Gera Valor: o investimento de embalagens sustentáveis (que não agridem o meio ambiente) agrega valor à marca, pois as pessoas passam a ver com bons olhos os empreendimentos que se preocupam com os recursos naturais;

- $\quad$ Posiciona a marca: a escolha de embalagens sustentáveis reflete a política da empresa, fazendo com que o consumidor passe a se identificar com a marca;

- Cria competitividade: uma marca ligada à responsabilidade ambiental e social faz com que a marca se destaque no mercado competitivo, pois os concorrentes que não se adaptarem a essa realidade e tendência de mercado logo terão que se adaptar a essa nova realidade (BIOCOPO, 2019)

\section{CONCLUSÃO}

A partir dos dados e elementos identificados durante a realização desta pesquisa, foi possível concluir que a questão dos resíduos sólidos é tema que merece atenção especial não somente no Brasil, mas em todo o Planeta, especialmente nas nações mais desenvolvidas e que são as maiores geradoras de embalagens.

A inexistência de políticas públicas que possam subsidiar o processo de tomada de decisão com relação ao setor empresarial efetivamente abraçar a ideia de utilizar embalagens sustentáveis para seus produtos é um fator limitador na busca pelo desenvolvimento sustentável.

É fato que o uso de embalagens tem se tornado indispensável para a sociedade (em especial a sociedade capitalista), pois desempenha diversas funções importantes tanto para garantir a qualidade do produto, quanto para sua comercialização. A partir dessa perspectiva, surge a preocupação com o destino final das embalagens e com os impactos que estas podem 


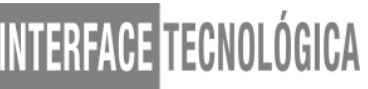

causar no meio ambiente, uma vez que possuem os mais diversos tipos de materiais com diferentes tempos de degradação, conforme abordado no decorrer desta pesquisa.

Constatou-se ainda que a busca pelo desenvolvimento de embalagens sustentáveis e uma necessidade, mas uma necessidade que poderia ter algum tipo de subsídio por parte do Poder Público, já que a busca pelo desenvolvimento sustentável é imposição legal a todos: sociedade e governo.

Neste sentido, a geração de embalagens recicláveis e biodegradáveis têm sido encaradas como alternativa na busca da redução pelos impactos ambientais, principalmente se nos reportarmos ao setor de alimentos, que devem buscar desenvolver embalagens que utilizam a menor quantidade possível de material para um mesmo produto.

\section{REFERÊNCIAS}

ABNT - ASSOCIAÇÃO BRASILEIRA DE NORMAS TÉCNICAS. ABNT. Sistemas da gestão ambiental Requisitos com orientações para uso. 2. [S. l.]: ABNT, 31 dez. 2004. Disponível em: <http://www.madeira.ufpr.br/disciplinasghislaine/iso-14001-2004.pdf>. Acesso em: 19 ago. 2019.

BIOCOPO. Benefícios de embalagens sustentáveis para sua empresa. Site: BioCOPO, 2019. Disponível em: <https://www.biocopo.com.br/beneficios-de-embalagenssustentaveis/>. Acesso em: 19 ago. 2019.

BRITO, M. O que é Gestão Ambiental e o que ela tem a ver com você?. UNIPÊ, 21 out. 2015. Disponível em: <http://blog.unipe.br/graduacao/o-que-e-gestao-ambiental-e-o-que-elatem-a-ver-com-voce>. Acesso em: 16 ago. 2019.

CAJAZEIRA, J. M. R. ISSO 14001: Manual de Implementação. Rio de Janeiro: Qualitymark, 1998.

CETESB; ABRE. Embalagem e Sustentabilidade: Desafios e orientações no contexto da Economia Circular. 1. ed. São Paulo: CETESB, 2016. 39 p. Disponível em:

<http://www.cetesb.sp.gov.br/>. Acesso em: 19 ago. 2019.

CONSELHO NACIONAL DO MEIO AMBIENTE-CONAMA. Lei no 306, de 5 de julho de 2002. LICENCIAMENTO AMBIENTAL - Normas e procedimentos. Publicada no DOU $n^{\circ}$ 138, Seção 1, páginas 75-76, 19 jul. 2002. Disponível em:

<http://www2.mma.gov.br/port/conama/legiabre.cfm?codlegi=306>. Acesso em: 15 ago. 2019

ECICLE. Embalagens sustentáveis: o que são, exemplos e vantagens. Site: ECicle, 2019. Disponível em: <https://www.ecycle.com.br/6316-embalagens-sustentaveis.html>. Acesso em: 19 ago. 2019. 


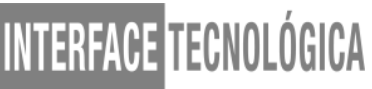

ELKINGTON, J. Canibais com Garfo e Faca. Makron Books: São Paulo, 2001

GRAZZIOTIN, L.; VIEIRA, G. Ensino do Design: Panorama dos diferentes cursos de Design no Brasil. 2014. 10 p. Artigo (Superior em Design) - Faculdade da Serra Gaúcha, [S. l.], 2014.

HOLMBERG, J. The university and transformation towards sustainability, International Journal of Sustainability in Higher Education, 2012. Disponível em: < https://www.emerald.com/insight/content/doi/10.1108/14676371211242544/full/html>. Acesso em: 04 de ago. 2019

ISTO É. A sopa de lixo no Pacífico: Cabem dois EUA na plataforma de sujeira encontrada no oceano e formada sobretudo por resíduos de plástico. Entrevistado: Charles Moore. Revista Istoé: Tecnologia \& Meio ambiente, [S. l.], ano 1997, 13 fev. 2008. Disponível em: https://istoe.com.br/790_A+SOPA+DE+LIXO+NO+PACIFICO/. Acesso em: 28 ago. 2019.

JANUÁRIO, Mauro, et al. Um estudo de comportamento ambiental da população wenceslau braz (no estado do parana) em relação a resíduos urbanos sólidos / estudo da performance ambiental da populacao de wenceslau braz / pr em relacao aos residuados wenceslau brasil / pr em relação a resíduos sólidos urbanos. " Revista de Gestão Ambiental e da Sustentabilidade, vol. 6, n. 1, 2017

MAZINI, E.; VEZZOLI, C. O Desenvolvimento de Produtos Sustentáveis: Os requisitos ambientais dos produtos industriais. Tradução: Astrid de Carvalho. 1. ed. rev. São Paulo: Edusp, 2005. 365 p. ISBN 8531407311.

MARQUES, J. R. O que é Gestão Ambiental. IBC Portal, [S. l.], 24 jun. 2015. Disponível em:< https://www.ibccoaching.com.br/portal/rh-gestao-pessoas/o-que-e-gestao-ambiental/>. Acesso em: 15 ago. 2019

MESTRINER, F. Design de embalagem: curso básico. $2^{\text {a }}$ Edição. São Paulo: Markon Books, 2002.

MINISTÉRIO DO MEIO AMBIENTE. MMA. O que é o CONAMA?. [S. l.]: MMA, 2011. Disponível em:< http://www2.mma.gov.br/port/conama/>. Acesso em: 16 ago. 2019.

MINISTÉRIO DO MEIO AMBIENTE. Qual é o impacto das embalagens no meio ambiente?. [S. l.]: MMA, 2017. Disponível em: https://www.mma.gov.br/responsabilidadesocioambiental/producao-e-consumo-sustentavel/consumo-consciente-deembalagem/impacto-das-embalagens-no-meio-ambiente.html. Acesso em: 28 ago. 2019.

MOURA, L. A. A. Qualidade e Gestão Ambiental: Sustentabilidade e ISO 14001. 6. ed. Belo Horizonte: Del Rey, 2011. p.423

MOURA, R.; BANZATO, J. M. Embalagem, utilização e conteinerização. São Paulo: IMAM, 1997.

ONU. Carta da Terra. Nações Unidas, 2002. Disponível em: <http://www.mma.gov.br/estruturas/agenda21/_arquivos/carta_terra.doc>. Acesso em: 15 ago. 2019 


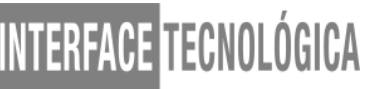

PEREIRA, J. L. Planejamento de embalagens de papel. Rio de Janeiro: 2AB, 2003.

PERFORM PAK. Embalagens Sustentáveis: o que são e quais os benefícios ao investir?. [S. l.]: PERFORM PAK, 19 set. 2018. Disponível em:

https://blog.performpak.com.br/embalagens-sustentaveis-o-que-sao-e-quais-os-beneficios-aoinvestir/. Acesso em: 28 ago. 2019.

ROMANO, G. Qual a real importância da embalagem na logística?. INTELIPOST, 6 nov. 2018. Disponível em: https://www.intelipost.com.br/blog/qual-a-importancia-da-embalagemna-logistica/. Acesso em: 28 ago. 2019.

SCHULTZ, P. W. Environmental attitudes na behaviors across cultures. In W. J. Lonner, D. L. Dinnel, S. A. Hayes, and D. N. Sattler. Online Readings in Psychology and culture (unit 8, chapter 4), Center for Cross Cultural Research, Western Washington University, Bellingham. Whashington USA (2002).

SILVA, D. J. P. Entendendo a ISO 14000. 2011. 12 p. Trabalho de Graduação (Curso superior de ciência e tecnologia de alimentos) - Universidade Federal de Viçosa, Viçosa MG, 2011. Disponível em:

<https://www2.cead.ufv.br/sgal/files/apoio/saibaMais/saibaMais6.pdf>. Acesso em: 19 ago. 2019.

SIQUEIRA, F. 8 tipos de embalagem que você precisa conhecer!. IDEIA, 5 abr. 2018. Disponível em: https://blog.ideiaembalagens.com.br/tipos-de-embalagem-que-voce-precisaconhecer/. Acesso em: 28 ago. 2019. 